\title{
Differential Responses of Two Rice Varieties to Perchlorate Stress
}

\author{
Guikui Chen ${ }^{1,2 *}$, Hongzhi He ${ }^{1,2}$, Haishuo Gao ${ }^{1,2}$, Huashou Li ${ }^{1,2}$, Zemin Zhang ${ }^{1 * * *}$ \\ 'College of Agriculture, South China Agricultural University, \\ 483 Wushan Road, Guanzhou 510642, China \\ ${ }^{2}$ Key Laboratory of Agro-Environment in the Tropics, Ministry of Agriculture, P.R. China, \\ South China Agricultural University, Guangzhou 510642, China
}

Received: 4 April 2014

Accepted: 3 August 2014

\begin{abstract}
Two rice varieties, one perchlorate-tolerant (Gannuoxiang, GN) and the other perchlorate-sensitive (IR65598-112-2, IR), were exposed to 20, 200, and $400 \mathrm{mg} / \mathrm{kg}$ soil perchlorate to investigate their physiological responses and perchlorate accumulation. It was found that perchlorate decreased leaf chlorophyll content in both rice varieties. The activities of superoxide dismutase (SOD) and catalase (CAT) decreased while peroxidase (POD) increased in both rice varieties under perchlorate stress at tillering stage. Rice variety IR showed earlier physiological response and was more affected by perchlorate than GN. Perchlorate induced physiological response in different ways depending on perchlorate contamination level, rice variety, and growing stage. Perchlorate concentration in leaves was significantly higher than that in roots, stems and seeds. Perchlorate accumulation in IR leaves was higher than GN, but GN stored more perchlorate in its edible portion at low perchlorate level. These results indicated that high sensitivity of the rice variety IR to perchlorate stress might be due to antioxidant enzymes in perchlorate-detoxification and its higher perchlorate accumulation in leaves.
\end{abstract}

Keywords: perchlorate, rice (Oryza sativa L.), antioxidant enzymes, accumulation, chlorophyll content

\section{Introduction}

Perchlorate can perturb thyroid hormone (TH) homeostasis by competitive inhibition of iodide uptake by the thyroid gland, and such effects are more pronounced under iodide-deficient nutrition [1]. The contamination of perchlorate in groundwater and surface water has been a concern since the late 1990s, but recently it has been detected in various foods, including fresh produce [2], milk [3], breast milk [4], baby formula [5], and also in human body fluids such as urine, saliva, and blood [6-8]. Some of these findings are reported to be the result of natural sources such as nitrate deposits or atmospheric deposition [9-11].

*e-mail: guikuichen@scau.edu.cn

**e-mail: zmzhang@scau.edu.cn (corresponding author)
Conversely, the perchlorate contamination of highest concentration and most concern was found from anthropogenic sources such as manufacturing facilities, military sites, and other places where human activities (like blasting and fireworks displays) have resulted in perchlorate releases to the environment $[12,13]$. With the intense investigations on the occurrence of perchlorate in the United States, it was clear that perchlorate can be considered as a widespread environmental contaminant [14]. Studies show that perchlorate has also been widespread in China and perchlorate levels in blood of Chinese adults are 10-fold greater than levels reported for U.S. adults [15-17]. This could relate to flourishing fireworks and aviation industrie. We detected the perchlorate level near several chemical plants in China and the concentration was about $1-50 \mathrm{mg} / \mathrm{L}$ in surface waters and $0.16-91.36 \mathrm{mg} / \mathrm{kg}$ in soil. 
The toxicity responses due to $\mathrm{ClO}_{4}^{-}$exposure have been reported in different plants and animals $[18,19]$. With the potential for food crop to be a significant source of perchlorate exposure in humans, and because phytoremediation has been suggested as a remediation option, a mechanistic understanding of perchlorate's phytotoxicity is warranted. Many reports showed environmental stresses such as drought stress [20], heavy metal stress [21], and salt stress [22] caused different physiological responses in rice varieties. As an oxidizer, perchlorate may also cause oxidative stress to rice plants. Some previous field and laboratory studies also show the ability for perchlorate accumulation is species-dependent [23-26] and genotype-dependent [27]. Rice (Oryza sativa L.) is one of the major food crops in many countries and there are many cultivars or varieties in the world. However, perchlorate accumulation in rice varieties as well as their physiological response to perchlorate stress has not been reported yet.

In our previous work [28], two rice varieties with varied perchlorate-sensitivity were selected from 24 rice varieties based on the great differences in their genetic backgrounds from different countries. The objectives of this study were to investigate the effects of perchlorate on chlorophyll content, antioxidant enzyme activities, and perchlorate accumulation in two rice varieties with different perchlorate-tolerance abilities.

\section{Material and Methods}

\section{Rice Varieties and Soil}

To investigate the differences between rice varieties in perchlorate tolerance, 24 rice varieties based on the great difference of their genetic background from nine counties were used in our previous study, and a hydroponic experiment was conducted in plant growth chamber under different perchlorate concentrations, including 0 (the control), 2.0, and $4.0 \mathrm{mmol} / \mathrm{L}$. Some growth characteristics such as plant height, root length, fresh biomass, dry biomass, etc. were measured. The data were analyzed by Hierarchical clustering analysis and the varieties were classified as sensitive, moderate, and tolerant to perchlorate. Gannuoxiang $(\mathrm{GN})$ is a perchlorate-resistance rice variety while IR65598-112-2 (IR) is a perchlorate-sensitive rice variety. Gannuoxiang is a kind of indica rice and its origin country is China. IR65598$112-2$ is a kind of japonica rice and its origin country is the Philippines. All of the seeds of the rice (Oryza sativa L.) varieties were supplied by Guangdong Provincial Key Lab of Plant Molecular Breeding.

The soil used for the pot experiment was collected from the surface layer $(20 \mathrm{~cm})$ of a paddy field in the Experimental Farm of the South China Agricultural University. The main properties of soil were shown in Table 1 .

\section{Experimental Design}

Rice seeds were soaked in sterilized water and then germinated at room temperature. When the seedlings
Table 1. Experimental soil properties.

\begin{tabular}{|c|c|c|c|}
\hline Characteristics & Value & Characteristics & Value \\
\hline $\mathrm{pH}$ & 6.28 & Ammonium N (mg/kg) & 27.35 \\
\hline Total N $(\mathrm{g} / \mathrm{kg})$ & 1.18 & Nitrate N $(\mathrm{mg} / \mathrm{kg})$ & 89.74 \\
\hline Total P $(\mathrm{g} / \mathrm{kg})$ & 0.86 & $\begin{array}{c}\text { Alkali-hydrolyzale N } \\
(\mathrm{mg} / \mathrm{kg})\end{array}$ & 157.26 \\
\hline Total K $(\mathrm{g} / \mathrm{kg})$ & 27.08 & Available P $(\mathrm{mg} / \mathrm{kg})$ & 47.73 \\
\hline $\begin{array}{c}\text { Organic matter } \\
\text { content }(\mathrm{g} / \mathrm{kg})\end{array}$ & 24.16 & Available K $(\mathrm{mg} / \mathrm{kg})$ & 142.93 \\
\cline { 3 - 4 } & Perchlorate $(\mathrm{mg} / \mathrm{kg})$ & not detected \\
\hline
\end{tabular}

were at 3-leaf age, uniform plants were selected and transplanted into plastic pots $(30 \mathrm{~cm} \times 50 \mathrm{~cm}$, diameter $\times$ height) containing $7 \mathrm{~kg}$ of soil in each pot. $\mathrm{KClO}_{4}$ solution was added into soil to form four perchlorate concentrations: 0 (control), 20, 200, and $400 \mathrm{mg} / \mathrm{kg}$. The soil was well mixed and soaked for 1 week prior to rice seedling transplanting. The experimental plot was completely randomized with 4 replications per treatment and six plants per repetition.

\section{Chlorophyll Content Determination}

At seedling, tillering, and heading stages, the second fully expanded leaves were selected for chlorophyll content measurement with a SPAD 502 Plus Chlorophyll Meter (Konica Minolta, Japan).

\section{Assay of Antioxidant Enzyme Activities}

At tillering and heading stages, the second fully expanded leaves were sampled for enzymatic analysis according to Chen and Wang [29]. SOD activity was assayed by monitoring the inhibition of photochemical reduction of nitro blue tetrazolium (NBT). One unit of SOD activity was expressed as the amount of enzyme required to cause $50 \%$ inhibition of the reduction of NBT as monitored at $560 \mathrm{~nm}$. POD activity was measured by following the change of absorption at $470 \mathrm{~nm}$ due to guaiacol oxidation. CAT activity was assayed as the rate of $\mathrm{H}_{2} \mathrm{O}_{2}$ decomposition at $240 \mathrm{~nm}$. The activities of SOD, POD, and CAT were expressed as enzyme units per gram fresh weight (U/g FW).

\section{Perchlorate Determination}

At maturity, the plants were separated into root, stem, leaf, and seed (grain with husk). All samples went through a series of pretreatment processes before analysis according to Shi et al. [15]. The pretreatment processes for soil, root, stem, leaf and seed of rice plants are as follows.

All plant samples were air-dried and ground into powder and then homogenized with a 35 -mesh $(0.5 \mathrm{~mm})$ sieve. 2.0 $\mathrm{g}$ of plant powder was weighed into a $50 \mathrm{~mL}$ conical flask 
along with $30 \mathrm{~mL} 18.0 \mathrm{M} \Omega / \mathrm{cm}$ deionized water (Milli-Q Water System, Millipore Corporation, Bedford, MA), and then extracted in a shaker at $200 \mathrm{rpm}$ for $3 \mathrm{~h}$ at room temperature. Then the mixture was centrifuged for another 25 min at $6,000 \mathrm{rpm}$. After that the supernatant solution was vacuum filtered through a $0.22 \mu \mathrm{m}$ polyethersulfone filter (Millipore Corp., Bedford, MA) then passed through a preconditioned ENVI-18 solid-phase extraction (SPE) cartridge (Supelco, Bellefonte, PA) to remove organic materials. The first $1.0 \mathrm{~mL}$ of sample pushed through the filter is discarded and the remaining aliquots are used for IC analysis.

Soil samples were freeze-dried and homogenized by sieving through a stainless steel 35 -mesh $(0.5 \mathrm{~mm})$ sieve. $5.0 \mathrm{~g}$ samples were weighed into a $50 \mathrm{~mL}$ conical flask added with $20 \mathrm{~mL}$ deionized water and then extracted in mechanical shaker at a speed of $200 \mathrm{rpm}$ for $3 \mathrm{~h}$ at room temperature. Then the mixture was centrifuged for $25 \mathrm{~min}$ at 6,000 rpm and the supernatant solution was taken out. At last, the $15 \mathrm{ml}$ of supernatant solution went through 0.22 $\mu \mathrm{m}$ polyethersulfone membrane filter, OnGuard $\mathrm{H}$ and OnGuard RP successively, which were used for the removal of solid substance, metallic ion, and hydrophobic compounds, respectively.

The quantification of perchlorate was performed on an ICS-900 ion chromatography (Dionex, US) according to Jackson et al. [23] with slight modification. The chromatographic column was IonPac AG20/AS20 and the temperature was maintained at $30^{\circ} \mathrm{C}$. The concentrations of $\mathrm{ClO}_{4}^{-}$in the samples were quantified by external calibration. Standard curves were calculated from injection of 50 to $50,000 \mu \mathrm{g} / \mathrm{L}$ calibration standards. Computer-generated peak areas were used to determine perchlorate concentrations. Based on injection of $10-\mu \mathrm{L}$ injections, the instrument detection limit for perchlorate in water was $20 \mu \mathrm{g} / \mathrm{L}$. A continuing calibration check was performed after every 10 samples, with a calibration standard to check for instrumental drift. Along with every 20 samples, a laboratory reagent blank, a laboratory fortified blank, and a laboratory fortified duplicate were analyzed. Each quality control sample was prepared similarly to the samples. Mean recovery of labeled internal standard spiked into water and soil samples were $99 \%$ and $86 \%$, respectively.

\section{Statistical Analysis}

Basic statistical analysis was performed with SPSS-13 statistical package (SPSS Inc., Chicago, IL, USA). Duncan's multiple range tests were used after the analysis of variance (ANOVA) $(\mathrm{p}<0.05)$. All data were presented as mean \pm standard error.

Plant-soil bioconcentration factor $(B C F)$ was calculated by the equation:

$$
B C F=C_{\text {plant }} / C_{\text {soil }}
$$

...where: $C_{\text {plant }}-$ concentration of perchlorate in plant (mg/kg dry wt) and $C_{\text {soil }}$ - concentration of perchlorate in soil (mg/kg dry wt).

\section{Results}

\section{Effects of Perchlorate on Chlorophyll Content}

Perchlorate greatly influenced chlorophyll content (Fig. 1). The most significant reductions were found when the plants exposed to $400 \mathrm{mg} / \mathrm{kg}$ perchlorate and the extent of reduction became greater with increased perchlorate levels. Meanwhile, the inhibition of chlorophyll content by perchlorate at tillering stage is much more obvious than that at seedling and heading stage. The results also showed a considerable variation in chlorophyll content between two rice varieties. IR showed more early response to perchlorate stress than GN.

(a)
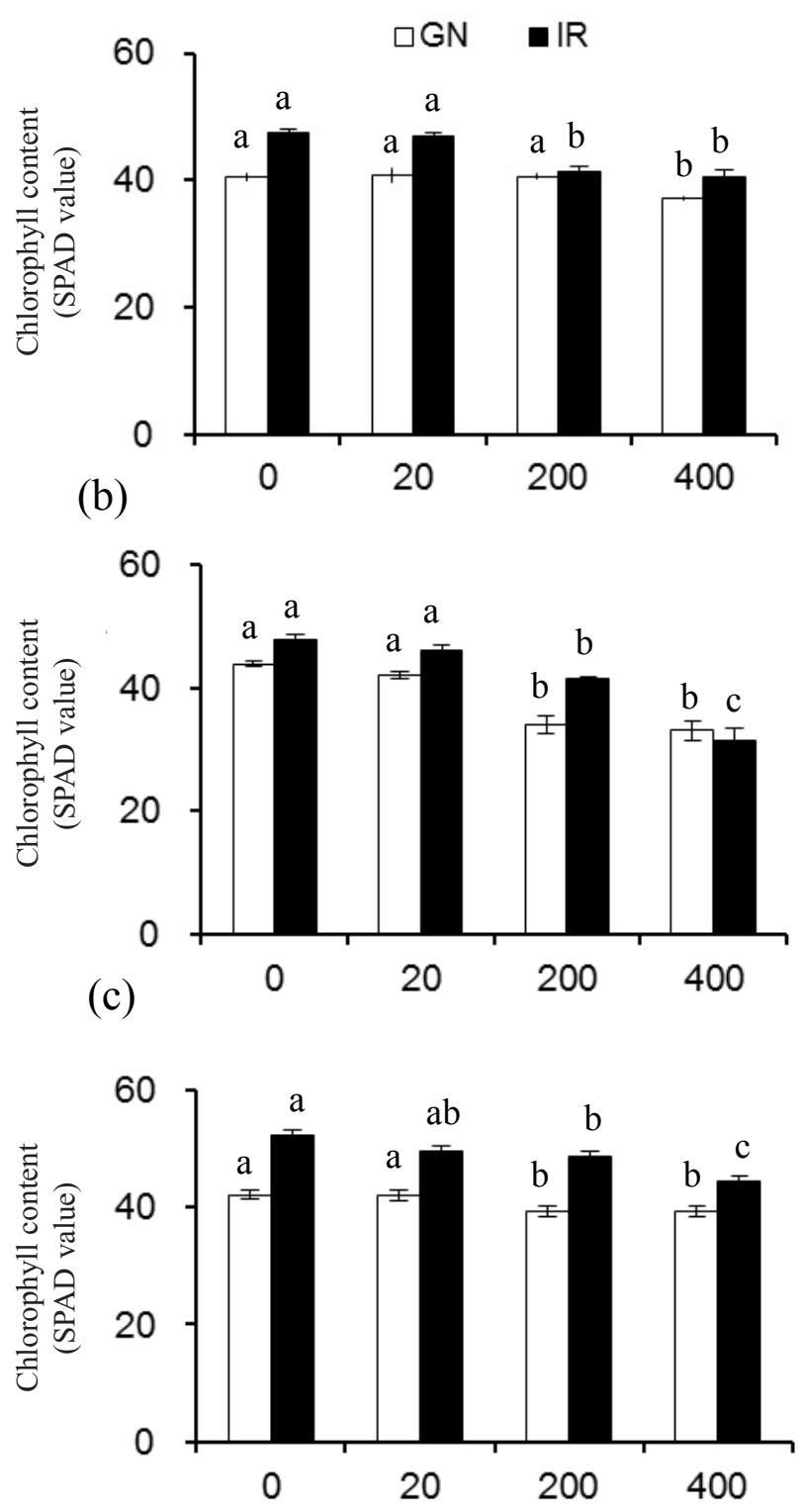

Fig. 1. Effect of perchlorate on relative chlorophyll content of leaf in two rice varieties at seedling stage (a), tillering stage (b), and heading stage $(\mathrm{c})$; bars represent the standard errors $(\mathrm{n}=24)$. Different letters indicate significant differences $(\mathrm{P}<0.05)$ among the treatments within each variety. 


\section{Effects of Perchlorate on Antioxidant Enzymes}

At tillering stage (Fig. 2a), the addition of 200 and 400 $\mathrm{mg} / \mathrm{kg}$ perchlorate caused a significant reduction in SOD activity for both rice varieties, and $20 \mathrm{mg} / \mathrm{kg}$ perchlorate also decreased SOD activity significantly for IR, but no such significant reduction was found for GN. In contrast, at heading stage there was no significant difference observed in the activity of SOD for GN variety, but IR variety treated with $400 \mathrm{mg} / \mathrm{kg}$ perchlorate still maintained significantly lower SOD activity (Fig. 2b).

(a)

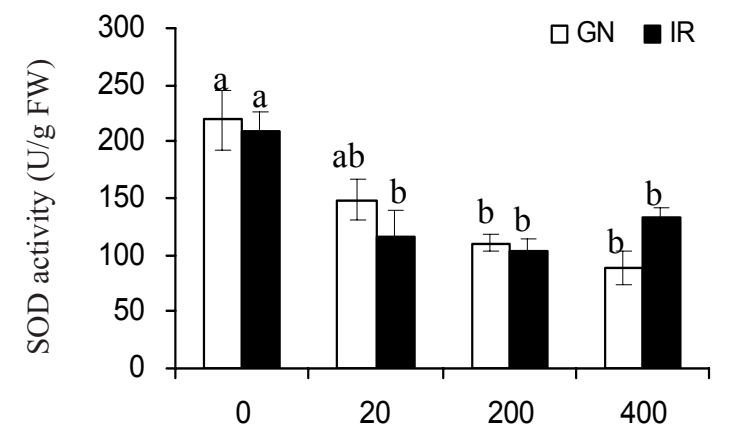

(c)

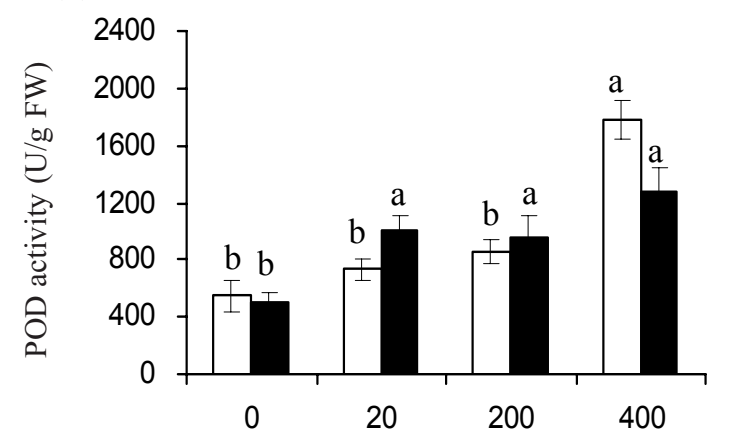

(e)

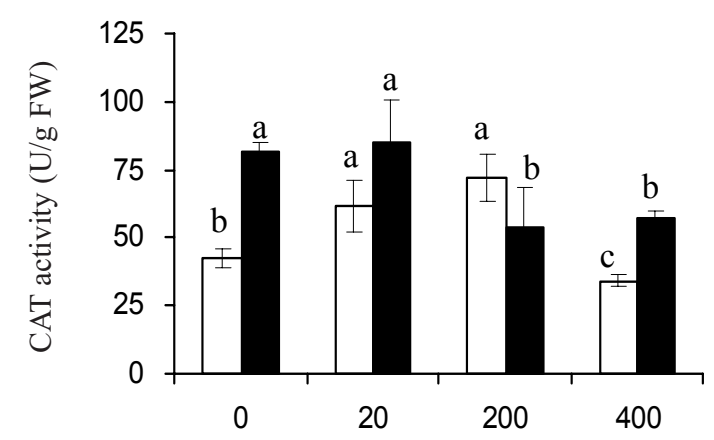

The current results showed that perchlorate addition significantly increased POD activity in IR variety at tillering stage (Fig. 2c), whereas in GN variety only $400 \mathrm{mg} / \mathrm{kg}$ soil perchlorate increased the POD activity. However, there was no significant difference in the POD activity of both rice varieties in response to perchlorate compared with their control at heading stage (Fig. 2d).

In this study, GN showed a significant increase in CAT activity at low and moderate concentration of perchlorate exposure (20 and $200 \mathrm{mg} / \mathrm{kg}$ ), followed by a decrease at high concentration $(400 \mathrm{mg} / \mathrm{kg})$ at tillering stage (Fig. 2e),

(b)

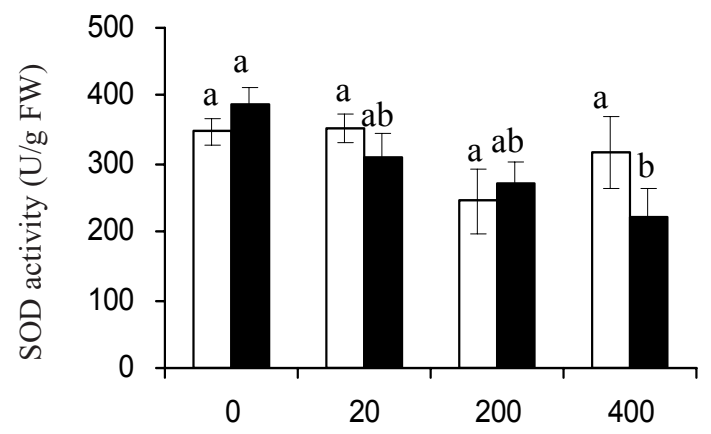

(d)

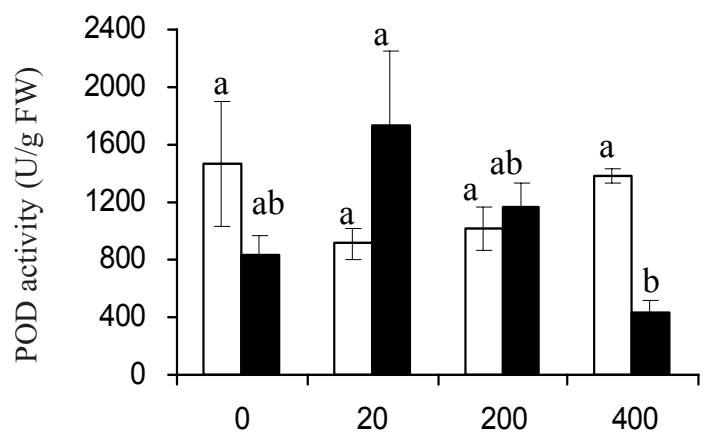

(f)

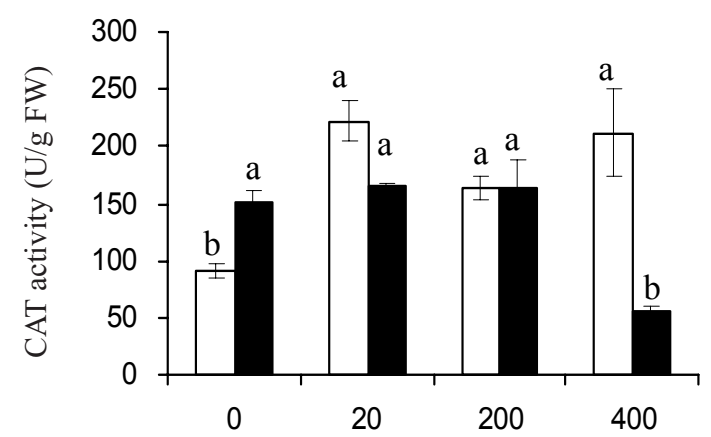

Perchlorate concentration $(\mathrm{mg} / \mathrm{kg})$

Fig. 2. Effects of perchlorate on superoxide dismutase (SOD), peroxidase (POD), and catalase (CAT) activities of leaf in two rice varieties: Gannuoxiang (GN) and IR65598-112-2 (IR). (a) SOD activity at tillering stage, (b) SOD activity at heading stage, (c) POD activity at tillering stage, (d) POD activity at heading stage, (e) CAT activity at tillering stage, (f) CAT activity at heading stage; bars represent the standard errors $(n=4)$. FW - fresh weight. Different lowercase letters indicate significant differences among the treatments of the same rice variety $(\mathrm{P}<0.05$, Duncan's test $)$. 
whereas IR showed significant decrease at moderate and high concentrations. At heading stage (Fig. 2f), GN showed a significant increase in response to the three perchlorate levels in CAT activity. Meanwhile, increased concentrations of perchlorate still led to reduced CAT activity in IR variety at heading stage.

\section{Perchlorate Accumulation in Different Tissues of Two Rice Varieties}

Perchlorate quantification (Fig. 3) was performed to verify the difference of perchlorate accumulation between rice varieties. Control plants without $\mathrm{ClO}_{4}^{-}$ added have shown no perchlorate has been detected. Perchlorate concentrations in leaves were much higher than that in roots, stems, and seeds in 200 and $400 \mathrm{mg} / \mathrm{kg}$ treatment. This indicated that rice leaf is the main organ for perchlorate accumulation. Significant differences in perchlorate accumulation between two rice varieties were observed. IR accumulated more perchlorate in leaves than $\mathrm{GN}$, and the bioconcentration factors (BCF) ranged from about 2.27 to 9.56 (Table 2). But GN stored more perchlorate in its edible portion at low and medium perchlorate level.

\section{Discussion of Results}

\section{Physiological Responses}

Chlorophyll content is an indication of responses in different plants subjected to different environmental stresses. In the present study, a detrimental effect of perchlorate toxicity on chlorophyll content was found. The results were in agreement with earlier findings that $\mathrm{Cd}$ stress decreased chlorophyll contents for both rice cultivars with Cd-sensitive genotype being more severely affected [21]. In our previous study, it was also observed that when treated with 500 $\mathrm{mg} / \mathrm{L}$ perchlorate, chlorophyll content of four wetland plants showed significant decline contrasted to control groups [30].

Being a strong oxidizing agent, perchlorate possibly destroyed the chloroplast membrane and induced exuberated reactive oxygen species. Thus disintegrating the thylakoid membrane might be observable, and as a result the rice plants were severely devoid of adequate chlorophyll content under the oxidative stress of perchlorate. However, there is no data available to explain how plants against oxidative stress induced by perchlorate through nonenzymatic constituents or the enzymatic constituents. (a)

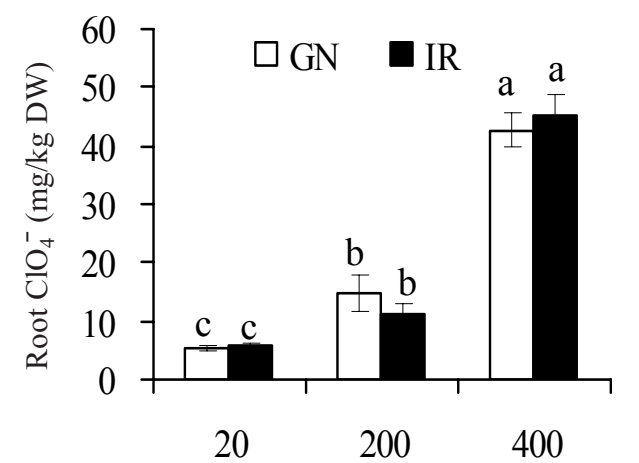

(c)

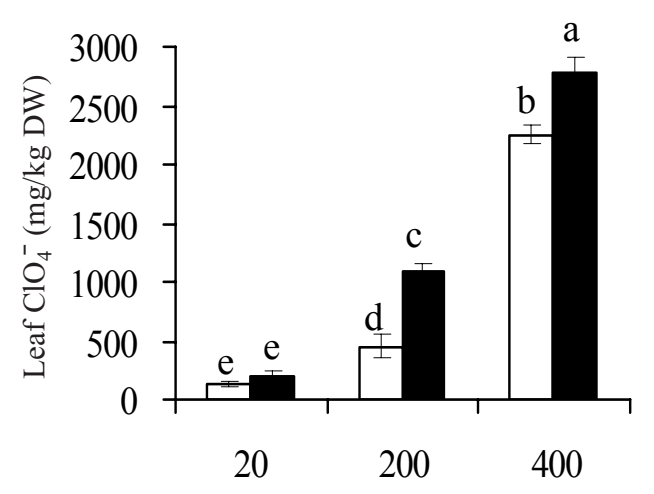

(b)

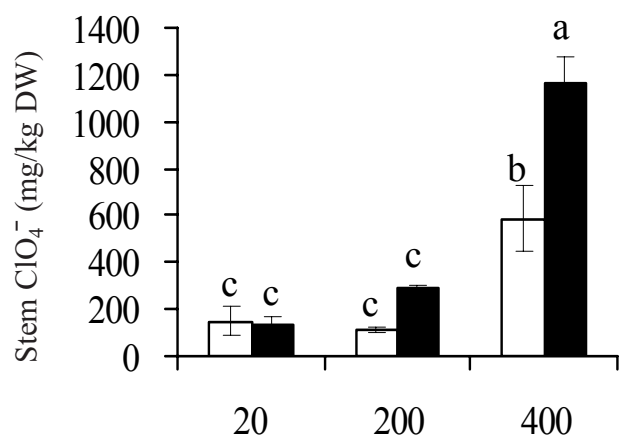

(d)

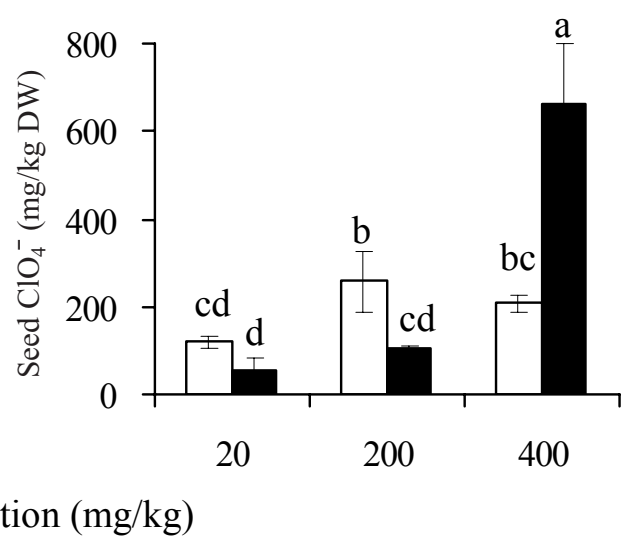

Fig. 3. Perchlorate accumulation in root (a), stem (b), leaf (c), and seed (d) of two rice varieties, Gannuoxiang (GN) and IR65598-112-2 (IR), at maturation stage; bars represent the standard errors. DW - dry weight. Different lowercase letters indicate significant differences $(\mathrm{P}<0.05)$ among the same tissue. 
Table 2. Bioconcentration factors (BCF) of perchlorate in two rice varieties.

\begin{tabular}{|c|c|c|c|c|c|}
\hline $\begin{array}{c}\text { Rice } \\
\text { varieties }\end{array}$ & $\begin{array}{c}\text { Perchlorate levels } \\
(\mathrm{mg} / \mathrm{kg})\end{array}$ & Root & Stem & Leaf & Seed (with husk) \\
\hline \multirow{3}{*}{ GN } & 20 & $0.26 \pm 0.02 \mathrm{a}$ & $7.56 \pm 2.91 \mathrm{a}$ & $6.67 \pm 0.99 \mathrm{a}$ & $5.99 \pm 0.67 \mathrm{a}$ \\
\cline { 2 - 6 } & 200 & $0.07 \pm 0.02 \mathrm{bc}$ & $0.58 \pm 0.06 \mathrm{c}$ & $2.27 \pm 0.51 \mathrm{~b}$ & $1.28 \pm 0.35 \mathrm{bc}$ \\
\cline { 2 - 6 } & 400 & $0.11 \pm 0.01 \mathrm{~b}$ & $1.46 \pm 0.35 \mathrm{c}$ & $5.63 \pm 0.19 \mathrm{ab}$ & $0.52 \pm 0.05 \mathrm{c}$ \\
\hline \multirow{3}{*}{ IR } & 20 & $0.30 \pm 0.01 \mathrm{a}$ & $6.70 \pm 1.80 \mathrm{ab}$ & $9.56 \pm 2.99 \mathrm{a}$ & $2.84 \pm 1.26 \mathrm{~b}$ \\
\cline { 2 - 6 } & 200 & $0.06 \pm 0.01 \mathrm{c}$ & $1.44 \pm 0.10 \mathrm{c}$ & $5.45 \pm 0.29 \mathrm{ab}$ & $0.52 \pm 0.02 \mathrm{c}$ \\
\cline { 2 - 6 } & 400 & $0.11 \pm 0.01 \mathrm{~b}$ & $2.90 \pm 0.29 \mathrm{bc}$ & $6.95 \pm 0.32 \mathrm{a}$ & $1.65 \pm 0.34 \mathrm{bc}$ \\
\hline
\end{tabular}

Values with different lowercase letters within a column are significantly different at $\mathrm{P}<0.05$

In the present study, activities of SOD, POD, and CAT were tested for the first time to reveal the role of ROS scavenging systems in combating the oxidative stress of perchlorate.

Antioxidative enzymes play crucial roles in detoxifying ROS. SOD catalyzes the conversion of $\mathrm{O}_{2}^{-}$to $\mathrm{H}_{2} \mathrm{O}_{2}$. The $\mathrm{H}_{2} \mathrm{O}_{2}$ is then decomposed in the presence of CAT and POD. The results of the present study confirm the finding that the activities of SOD decreased with increases in Cd levels for both rice cultivars with different grain cadmium accumulation [31]. Basu et al. also demonstrated the activities of SOD were decreased in IR-29 (salt-sensitive) and PB (aromatic Pusa Basmati), whereas they were unaltered in Pokkali (salt-tolerant) when they were subjected to drought stress for two days [20]. But some studies show SOD activity will be enhanced when plants are subjected to environmental stresses $[32,33]$. However, the response of SOD activity to environmental stresses is reported to be dependent on stress intensity, species, and age of the plants exposed to stress $[31,34,35]$.

POD is regarded as a crucial enzyme for the removal of reactive oxygen species (ROS) and decomposition of $\mathrm{H}_{2} \mathrm{O}_{2}$. Previous reports have shown that environmental stress such as salt stress [32], osmotic stress [33], and Cd [35] caused a significant increase in POD activities in different wheat or rice cultivars. The current results also showed perchlorate addition significantly increased POD activity at tillering stage, but there was no significant difference at heading stage. A number of studies indicated that POD activity response to environmental stress vary among plant species and among different cultivars [36, 37].

CAT is $\mathrm{H}_{2} \mathrm{O}_{2}$ capturing enzymes. It was suggested that the higher activities of CAT reduced $\mathrm{H}_{2} \mathrm{O}_{2}$ levels in the cell and enhanced the stability of membranes and $\mathrm{CO}_{2}$ fixation because several enzymes of the Calvin cycle in chloroplasts are very sensitive to $\mathrm{H}_{2} \mathrm{O}_{2}$. However, reports on the effect of environmental stress on CAT activity have been inconsistent $[20,31,32]$. In this study, both varieties show a significant increase and then followed by a decrease with the increased concentration of perchlorate.

In the present study, perchlorate induced different antioxidative responses at different rice stages and perchlo- rate concentrations. The general trend showed that stronger stimulations of enzymes were measured at tillering stage and higher concentrations than that at the heading stage and low concentration for both varieties as compared to controls. Considerable variations in antioxidant enzyme activities were also found between two rice varieties, and IR was affected more than GN. Based on these results, we presumed that the response of antioxidant enzymes in rice varieties to perchlorate stress might be dependent on perchlorate concentration, treatment time, rice variety, and rice growing stage.

\section{Perchlorate Accumulation}

Many studies have reported significant differences regarding the perchlorate accumulation among species [18, 23-26] or among genotypes within the same species [27]. These differences are of great interest to agriculture. But there is no information on rice varieties as related to perchlorate accumulation. According to our results, GN evaluated more risk of food contamination with $\mathrm{ClO}_{4}^{-}$at low and medium levels, since it accumulated more perchlorate in their seeds. Certain plants are able to metabolize high concentrations of perchlorate within their leaves (phytodegradation), although this process is slower than ex situ microbial degradation in the root zone (rhizodegradation) [18, 38]. Whereas perchlorate exhibited no significant movement from older leaves to new leaves of lettuce that was grown at solution concentrations of 10 or $50 \mathrm{ug} / \mathrm{liter}$ [39]. Perchlorate accumulation in rice may present a health hazard to humans and animals.

The variety IR showed higher perchlorate contents in the leaves, as well as its enzyme activities and chlorophyll levels were more affected compared to the variety GN. Thus, perchlorate induced the physiological response that appears to provide evidence about the pechlorate accumulation in rice varieties. However, perchlorate accumulation is not simply a passive process in higher plants [27]. Could GN have an exclusion mechanism that IR does not? Future functional characterization studies will be needed to determine the contribution of transporter genes that are responsible for perchlorate uptake. 


\section{Conclusions}

In summation, we demonstrated that considerable variations in chlorophyll content, antioxidant enzyme activities, and perchlorate accumulation were found between two rice varieties treated with perchlorate. It revealed that high sensitivity of the rice variety IR to perchlorate stress might be due to antioxidant enzymes in perchlorate-detoxification and its higher perchlorate accumulation in leaves.

\section{Acknowledgements}

Our study was funded by National Natural Science Foundation of China (30700099), the Science and Technology Program of Guangdong (2010B020301008), the Natural Science Foundation of Guangdong province (S2011010001055), and the Science and Technology Program of Guangzhou (2012J4300056).

\section{References}

1. KUNISUE T., FISHER J.W., KANNAN K. Modulation of thyroid hormone concentrations in serum of rats coadministered with perchlorate and iodide-deficient diet. Arch. Environ. Contam. Toxicol. 61, 151, 2011.

2. SANCHEZ C.A., BLOUNT B.C., VALENTIN-BLASINI L., KRIEGER R.I. Perchlorate, thiocyanate, and nitrate in edible cole crops (Brassica sp.) produced in the Lower Colorado River region. Bull. Environ. Contam. Toxicol. 79, 655, 2007.

3. GURUGE K.S., WU Q., KANNAN K. Occurrence and exposure assessment of perchlorate, iodide and nitrate ions from dairy milk and water in Japan and Sri Lanka. J. Environ. Monit. 13, 2312, 2011.

4. KIRK A.B., DYKE J.V., MARTIN C.F., DASGUPTA P.K. Temporal patterns in perchlorate, thiocyanate, and iodide excretion in human milk. Environ. Health Perspect. 115, $182,2007$.

5. HER N., KIM J., YOON Y. Perchlorate in dairy milk and milk-based powdered infant formula in South Korea. Chemosphere. 81, 732, 2010.

6. BLOUNT B.C., PIRKLE J.L., OSTERLOH J.D., VALENTIN-BLASINI L., CALDWELL K.L. Urinary perchlorate and thyroid hormone levels in adolescent and adult men and women living in the United States. Environ. Health Perspect. 114, 1865, 2006.

7. KANNAN K., PRAAMSMA M.L., OLDI J.F., KUNISUE T., SINHA R.K. Occurrence of perchlorate in drinking water, groundwater, surface water and human saliva from India. Chemosphere. 76, 22, 2009.

8. OLDI J.F., KANNAN K. Perchlorate in human blood serum and plasma: Relationship to concentrations in saliva. Chemosphere. 77, 43, 2009.

9. JACKSON W.A., BOHLKE J.K., GU B., HATZINGER P.B., STURCHIO N.C. Isotopic composition and origin of indigenous natural perchlorate and co-occurring nitrate in the southwestern United States. Environ. Sci. Technol. 44, 4869, 2010.

10. RAO B., ANDERSON T.A., REDDER A., JACKSON W.A. Perchlorate formation by ozone oxidation of aqueous chlorine/oxy-chlorine species: role of ClxOy radicals. Environ. Sci. Technol. 44, 2961, 2010.
11. CALDERON R., PALMA P., PARKER D., MOLINA M., GODOY F.A., ESCUDEY M. Perchlorate Levels in Soil and Waters from the Atacama Desert. Arch. Environ. Contam.Toxicol. 66, 155, 2014.

12. WILKIN R.T., FINE D.D., BURNETT N.G. Perchlorate behavior in a municipal lake following fireworks displays. Environ. Sci. Technol. 41, 3966, 2007.

13. WU Q., OLDI J.F., KANNAN K. Fate of perchlorate in a manmade reflecting pond following a fireworks display in Albany, New York, USA. Environ. Toxicol. Chem. 30, 2449, 2011.

14. PARKER D.R. Perchlorate in the environment: the emerging emphasis on natural occurrence. Environ. Chem. 6, 10, 2009.

15. SHI Y., ZHANG P., WANG Y., SHI J., CAI Y., MOU S., JIANG G. Perchlorate in sewage sludge, rice, bottled water and milk collected from different areas in China. Environ. Int. 33, 955, 2007.

16. WU Q., ZHANG T., SUN H., KANNAN K. Perchlorate in tap water, groundwater, surface waters, and bottled water from China and its association with other inorganic anions and with disinfection byproducts. Arch. Environ. Contam. Toxicol. 58, 543, 2010.

17. ZHANG T., WU Q., SUN H.W., RAO J., KANNAN K. Perchlorate and iodide in whole blood samples from infants, children, and adults in Nanchang, China. Environ. Sci. Technol. 44, 6947, 2010.

18. SEYFFERTH A.L., PARKER D.R. Uptake and fate of perchlorate in higher plants. Advances in Agronomy. 99, 101, 2008.

19. BERNHARDT R.R., HIPPEL F.A.V., O'HARA T.M. Chronic perchlorate exposure causes morphological abnormalities in developing stickleback. Environ. Toxicol. Chem. 30, 1468, 2011.

20. BASU S., ROYCHOUDHURY A., SAHA P., SENGUPTA D. Differential antioxidative responses of indica rice cultivars to drought stress. Plant Growth Regulation. 60, 51, 2010.

21. CAI Y., LIN L., CHENG W., ZHANG G., WU F. Genotypic dependent effect of exogenous glutathione on Cd-induced changes in cadmium and mineral uptake and accumulation in rice seedlings (Oryza sativa). Plant, Soil Environ. 56, 516, 2010.

22. NOUNJAN N., THEERAKULPISUT P. Effects of exogenous proline and trehalose on physiological responses in rice seedlings during salt-stress and after recovery. Plant, Soil Environ. 58, 309, 2012.

23. JACKSON W.A., JOSEPH P., LAXMAN P., TAN K., SMITH P.N., YU L., ANDERSON T.A. Perchlorate accumulation in forage and edible vegetation. J. Agric. Food Chem. 53, 369, 2005.

24. HA W., SUAREZ D.L., LESCH S.M. Perchlorate uptake in spinach as related to perchlorate, nitrate, and chloride concentrations in irrigation water. Environ. Sci. Technol. 45, 9363, 2011.

25. BHASKARAN K., VIJAYA NADARAJA A., TUMBATH S., BABU SHAH L., GANGADHARAN PUTHIYA VEETIL P. Phytoremediation of perchlorate by free floating macrophytes. J. Hazard. Mater. 260, 901, 2013.

26. GRANTZ D.A., BURKEY K.O., JACKSON W.A., VU H.B., MCGRATH M.T., HARVEY G. Perchlorate content of plant foliage reflects a wide range of species-dependent accumulation but not ozone-induced biosynthesis. Environ. Pollut. 184, 690, 2014

27. SEYFFERTH A.L., PARKER D.R. Effects of genotype and transpiration rate on the uptake and accumulation of perchlorate $\left(\mathrm{ClO}_{4}^{-}\right)$in lettuce. Environ. Sci. Technol. 41, 3361, 2007. 
28. CHEN G. LUO S., HE H., ZHANG Z., LI H. Effect of perchlorate stress on the growth and development of rice and its nutrient uptake. Acta Ecologica Sinica. 34, 2014 [In Chinese, English summary] http://dx.doi.org/10.5846/stxb201301090066

29. CHEN J., WANG X. The experimental guide of plant physiology. South China University of Technology Press: Guangzhou, pp. 68-81, 2006 [In Chinese].

30. HE H., GAO H., CHEN G., LI H., LIN H., SHU Z. Effects of perchlorate on growth of four wetland plants and its accumulation in plant tissues. Environ. Sci. Pollut. Res. 20, 7301, 2013.

31. HASSAN M.J., SHAO G., ZHANG G. Influence of cadmium toxicity on growth and antioxidant enzyme activity in rice cultivars with different grain cadmium accumulation. J. Plant Nutrition. 28, 1259, 2005.

32. BHUTTA W.M. Antioxidant activity of enzymatic system of two different wheat (Triticum aestivum L.) cultivars growing under salt stress. Plant, Soil Environ. 57, 101, 2011.

33. WU G.Q., ZHANG L.N., WANG Y.Y. Response of growth and antioxidant enzymes to osmotic stress in two different wheat (Triticum aestivum L.) cultivars seedlings. Plant, Soil Environ. 58, 534, 2012.
34. SHAH K., KUMAR R.G., VERMA S., DUBEY R.S. Effect of cadmium on lipid peroxidation, superoxide anion generation and activities of antioxidant enzymes in growing rice seedlings. Plant Science. 161, 1135, 2001.

35. JALLOH M.A., CHEN J., ZHEN F., ZHANG G. Effect of different $\mathrm{N}$ fertilizer forms on antioxidant capacity and grain yield of rice growing under Cd stress. J. Hazard. Mater. 162, 1081, 2009.

36. HOJATI M., MODARRES-SANAVY S.A.M., KARIMI M., GHANATI F. Responses of growth and antioxidant systems in Carthamus tinctorius L. under water deficit stress. Acta Physiol. Plant. 33, 105, 2011.

37. XU H., SUN X., SHI Q., YANG F., YANG X., WANG X. Physiological responses of two cucumber cultivars to nitrate stress. J. Plant Nutrition, 35, 2167, 2012.

38. VAN AKEN B., SCHNOOR J.L. Evidence of perchlorate $\left(\mathrm{ClO}_{4}^{-}\right)$reduction in plant tissues (poplar tree) using radiolabeled $36 \mathrm{ClO}_{4}^{-}$. Environ. Sci. Technol. 36, 2783, 2002.

39. SEYFFERTH A.L., STURCHIO N.C., PARKER D.R. Is perchlorate metabolized or re-translocated within lettuce leaves? A stable-isotope approach. Environ. Sci. Technol. 42, 9437, 2008. 